\title{
Comparison of the left ventricular apex versus other arterial cannulation sites for the operative management of acute type $\mathrm{A}$ aortic dissection
}

\author{
Petar M Vukovic , Slobodan Micovic, Miodrag Peric, Predrag Milojevic, Ivan Nesic, Mladen Boricic, \\ Bosko Djukanovic \\ From World Society of Cardiothoracic Surgeons 25th Anniversary Congress, Edinburgh \\ Edinburgh, UK. 19-22 September 2015
}

\section{Background/Introduction}

The selection of the arterial inflow site for cardiopulmonary bypass during surgical treatment of patients with acute aortic dissection remains a very important issue. Several arterial cannulation sites, including left ventricular apex, were popularized over the years.

\section{Aims/Objectives}

The aim of the study was to analyse the influence of transapical cannulation on the outcomes of surgical treatment of acute type A aortic dissection.

\section{Method}

Between January 2010 and January 2015, emergent surgical aortic repair was performed in 158 consecutive patient with acute type A aortic dissection. In all patients open distal anastomosis was performed using deep hypothermic circulatory arrest. Patients were divided into two groups: transapical cannulation group and other cannulation sites group (including femoral and axillary artery cannulation). Operative variables and intrahospital outcomes were compared between groups.

\section{Results}

The most frequent cannulation site was the transapical cannulation (103 patients, 65.2\%). The other sites cannulation group (55 patients, 34.8\%) included 33 patients with femoral and 22 patients with axillary artery cannulation. The mortality rate for the entire cohort was $17.7 \%$. The mortality rate in the transapical group was $17.5 \%$ and $18.2 \%$ when other arterial cannulation sites were performed $(\mathrm{p}=0.91)$. There was no difference in major intrahospital outcomes between groups: postoperative stroke rate was $7.8 \%$ in transapical group and $9.1 \%$ in other cannulation sites group $(\mathrm{p}=0.77)$, myocardial infarction rate was $4.9 \%$ vs $5.5 \%$, (transapical group vs other cannulation sites group respectively, $\mathrm{p}=$ 0.87 ), and the incidence of postoperative acute renal failure in transapical group was $9.7 \%$ vs. $9.1 \%$ in the other cannulation sites group $(\mathrm{p}=0.9)$.

\section{Discussion/Conclusion}

This study suggests that transapical cannulation can be routinely used as a fast and safe method to establish cardiopulmonary bypass in patients with type A aortic dissection. No difference in operative outcomes was found when transapical cannulation was compared to the other cannulation sites.

Published: 16 December 2015

doi:10.1186/1749-8090-10-S1-A164

Cite this article as: Vukovic et al: Comparison of the left ventricular apex versus other arterial cannulation sites for the operative

management of acute type A aortic dissection. Journal of Cardiothoracic Surgery 2015 10(Suppl 1):A164. 